\title{
Decommissioning Plan for European Spallation Source
}

\author{
Daniela Ene $e^{1, a}$ \\ ${ }^{1}$ ESS ERIC, Environment Safety \& Health Department, Lund, Sweden
}

\begin{abstract}
This paper is a survey of the European Spallation Source initial decommissioning plan developed in compliance with Swedish Regulatory Authority requirements. The report outlines the decommissioning strategy selected and the baseline plan for decommissioning. Types and quantities of radioactive waste estimated to be generated at the final shut-down of the facility are further provided. The paper ends up with the analysis of the key elements of the decommissioning plan and the recommendations to the ESS management team..
\end{abstract}

\section{Context}

The European Spallation Source ERIC (ESS) is the European common effort in designing and building a next generation large-scale user facility for studies of the structure and dynamics of materials. The proposed schematic layout of the ESS facility is based on a linear driver (linac) directing the proton beam (5 MW of 2 $\mathrm{GeV}$ ) of $2.8 \mathrm{~ms}$ long pulses with a $20 \mathrm{~Hz}$ on a tungsten target where neutrons are produced via spallation reactions. Further the neutrons will be moderated to thermal and subthermal energies in a couple of moderators placed around the target. The moderators feed 22 beamlines guiding the neutrons to the scattering instruments, mainly for neutron scattering research.

The envisaged period for the decommissioning of the ESS facility is 2065 - 2070 after an expected 40 years of lifetime. This paper is a survey of the ESS initial decommissioning plan developed in compliance with Swedish Regulatory Authority requirements defined for non-nuclear facilities, and following also the guidance provided by Swedish Nuclear Fuel and Waste Management Company (SKB).

\section{Decommissioning strategy}

The initial decommissioning plan is the first step, of the graded approach that should be applied to the development of the ESS decommissioning plan, in agreement with the international and national guidance. It is based on the status of the ESS-project, as reported in the Technical Design Report [1].

Based on comparative analysis of several parameters ESS selected as referenced decommissioning strategy: immediate dismantling option. The desirable final goal of

\footnotetext{
$\overline{{ }^{a} \text { Daniela Ene: Daniela.ene }} @$ esss.se
}

decommissioning activities will be to return the site to green field status.

\section{Baseline plan for decommissioning}

The baseline plan for decommissioning consists of removing the components in a sequence starting with the most radioactive parts and ending with the least radioactive ones. Main tasks and time-scaling are roughly shown in Table 1.

Table 1. Main tasks of the ESS decommissioning project.

\begin{tabular}{|c|c|}
\hline Schedule & Task \\
\hline Phase \#1 & Remove highly activated components \\
\hline Phase \#2 & Remove other ILW \\
\hline Phase \#3 & Remove other LLW \\
\hline Phase \#4 & $\begin{array}{c}\text { Radiological clearance of buildings } \\
\text { and site }\end{array}$ \\
\hline
\end{tabular}

The approach to be used involves the dismantling, segmenting and decontamination techniques that are expected to be effective for the ESS facility. A summary of the methodologies and types of equipment recommended for application in each of the area of the facility is furfer provided.

\section{Radioactive waste expected at shut- down}

All radioactive waste from ESS will be handled and disposed of within the Swedish system for management of radioactive waste. The waste classification system 
used within this work is in accordance with Swedish policy and practice that define the following waste classes: i) free release material; ii) very low level waste (VLLW); iii) SFR-waste: short-lived; iv) SFL-waste: long-lived low-and intermediate level waste (LL-ILW); v) Heat generating waste. Swedish regulatory guidelines were used to classify ESS waste based on clearance index approach. The simplified scheme of ESS radwaste streams is provided in the Figure 1.

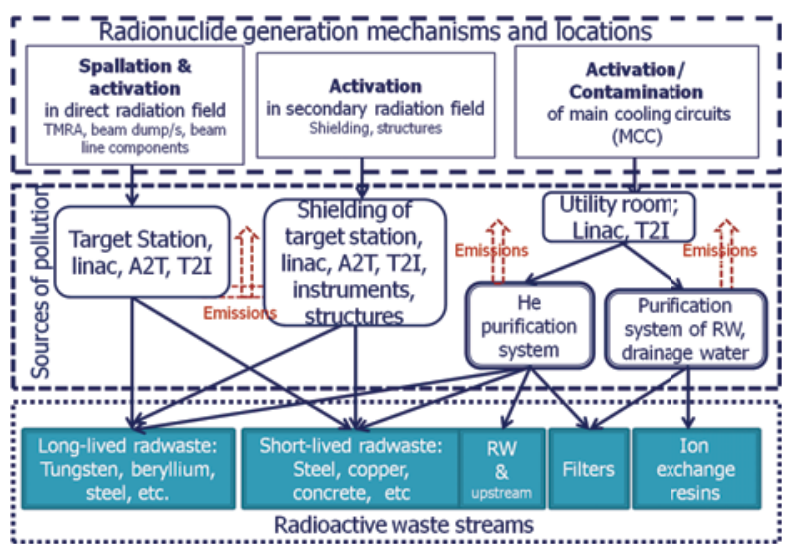

Figure 1. Simplified scheme of ESS radwaste streams

\subsection{Waste radiological characterization}

The amounts of ESS radioactive waste and classifications were derived using: i) precise calculations performed by means MCNPX2.6.0 [2] coupled with CINDER'90 [3] computer codes ii) scaling the activity from the operation experience of the existing spallation source installations for waste such it is difficult to predict level of activation or for components of the facility in stage of the preconceptual model.

For illustration purpose two examples are provided here. Firstly, the characterisation of the highest activated component, the tungsten target, that have a life time of five years. Table 2 . gives the target classification in terms of waste based on the specific activity and its decay heat at various decay times after shut-down.

Table 2. Activity and decay heat as a function of decay time for tungsten target.

\begin{tabular}{|c|c|c|c|}
\hline Decay time & $\begin{array}{c}\text { Specific } \\
\text { activity } \\
\left(\mathrm{TBq} / \mathrm{m}^{3}\right)\end{array}$ & $\begin{array}{c}\text { Decay } \\
\text { Heat } \\
\left(\mathrm{kW} / \mathrm{m}^{3}\right)\end{array}$ & Waste level \\
\hline 0 & $2.46 \mathrm{E}+06$ & $2.17 \mathrm{E}+02$ & \multirow{5}{*}{ HLW } \\
\hline 1week & $5.86 \mathrm{E}+05$ & $1.67 \mathrm{E}+01$ & \\
\hline $1 \mathrm{y}$ & $6.32 \mathrm{E}+04$ & $1.87 \mathrm{E}+00$ & \\
\hline $3 y$ & $2.28 \mathrm{E}+04$ & $6.31 \mathrm{E}-01$ & \\
\hline $5 y$ & $1.56 \mathrm{E}+04$ & $3.14 \mathrm{E}-01$ & \\
\hline $7 y$ & $1.19 \mathrm{E}+04$ & $1.66 \mathrm{E}-01$ & ILW \\
\hline
\end{tabular}

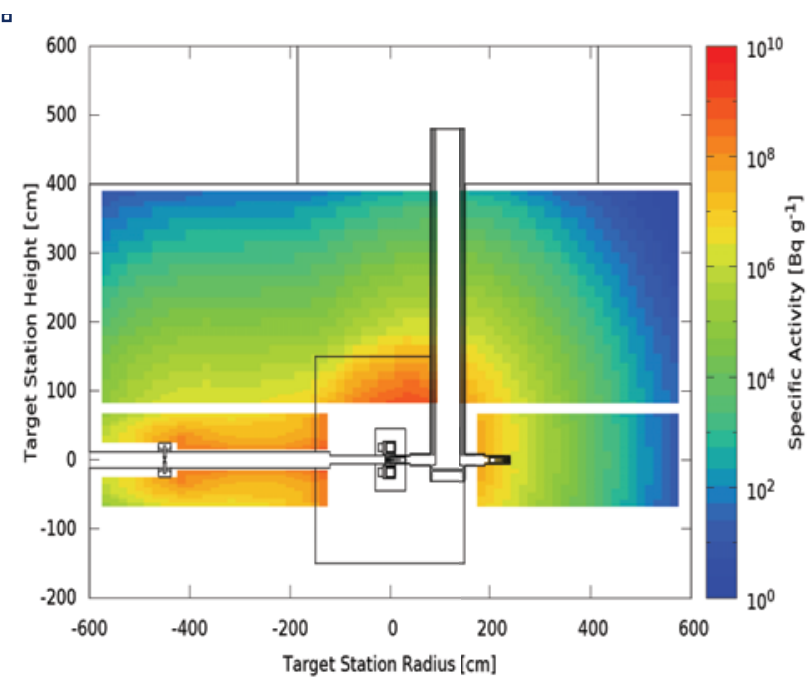

Figure 2. Specific activity of the target monolith at the final shut-down (40 years).

While the Figure 2 displays the map of the specific activity of a component having the lifetime of the facility, the shielding monolith.

Types and quantities of radioactive waste estimated to be generated at the final shut-down of the facility are further outlined.

Radwaste logistics developed at the ESS facility, during operations [4] was adapted to be used for decommissioning operations as well.

\subsection{Summary of radwaste at shut-down}

The sum-up of waste arising from entire ESS facility as decommissioning waste is provided. Decommissioning waste is breaking down in following categories:

- 11000 tons of metal waste, mainly Fe from the target monolith and the linac components dismantling likely to be SFR type waste;

- 1000 tons of waste may potentially be SFL type coming from parts of ILW from accelerator machine (10\% from the total amount) and TS shielding monolith placed closest to the target (20\% from the total);

- 3500 tons of concrete waste originating from the internal side of accelerator tunnel;

- 32000 tons of concrete VLLW from the dismantling of the shielding of the NBLs and instruments to be free released on site after to the storage for decay, if necessary;

- 800 tons of concrete VLLW from the dismantling of the Target monolith;

- 4000 tons of soil surrounding the concrete wall of the linac to be free released on site after to the storage for decay, if necessary.

Total generated decommissioning waste is about 58200 tons, from which $72 \%$ is expected to be free released. Note that the Clearance index of the soil around the concrete wall of the accelerator was also estimated and it was found that about one decay year after shutdown is enough to wait until the soil will be free released. 


\section{Key elements of decommissioning plan}

The key elements of the decommissioning plan :

- Licensing conditions;

- Staffing and training;

- Organization and administrative control;

- Cost estimation;

- Waste management;

- Emergency management;

- Radiation and physical protection;

- On and off site monitoring;

- Quality assurance

are further presented and discussed, with emphasis upon the cost estimation.

The paper ends up with the recommendations to the ESS management team of actions that can be taken during the design phase for efficient dismantling and disposal and thus reducing any exposure levels of the personnel and decommissioning costs.

\section{Conclusion}

The main outcome of this report is the descriptions provided on all waste types arising during the decommissioning of ESS facility and the waste management considered. The waste amounts reported here are based upon the baseline design of the facility whose design now enters a more refined stage. The operation/maintenance plans of the facility shall be developed and optimized as well. Therefore the current data are estimations subjected to evolutions and regular updates

\section{References}

1. http://www.esss.se/ Technical Design Report, (2013)

2. D. B. Pelowitz, MCNPX User's Manual. Version 2.6.0. s.1.: Los Alamos National Laboratory, LA-CP07-1473 (LANL, 2008).

3. Wilson, W. B. et al. "A manual for CINDER.90 version 07.4 and associated codes and data." 2007.

4. D. Ene, ESS Preliminary Waste Management Plan of European Spallation Source - 96154, Proceding of ICEM2013, Brusselles, Belgium, (2013). 